This is an electronic reprint of the original article. This reprint may differ from the original in pagination and typographic detail.

Author(s): Korhonen, Hanna; Heikkinen, Hannu L.T.; Kiviniemi, Ulla; Tynjälä, Päivi

Title: $\quad$ Student teachers' experiences of participating in mixed peer mentoring groups of inservice and pre-service teachers in Finland

Year: $\quad 2017$

Version:

Please cite the original version:

Korhonen, H., Heikkinen, H. L., Kiviniemi, U., \& Tynjälä, P. (2017). Student teachers' experiences of participating in mixed peer mentoring groups of in-service and preservice teachers in Finland. Teaching and Teacher Education, 61, 153-163. https://doi.org/10.1016/j.tate.2016.10.011

All material supplied via JYX is protected by copyright and other intellectual property rights, and duplication or sale of all or part of any of the repository collections is not permitted, except that material may be duplicated by you for your research use or educational purposes in electronic or print form. You must obtain permission for any other use. Electronic or print copies may not be offered, whether for sale or otherwise to anyone who is not an authorised user. 


\title{
Student teachers' experiences of participating in mixed peer mentoring groups of in-service and pre-service teachers in Finland
}

\begin{abstract}
This article examines from the student perspective a new Finnish model of teacher development that uses the peer group mentoring (PGM) method for combining preservice and in-service teacher education. Reflective reports of student teachers $(\mathrm{N}=19)$ who participated in PGM were analyzed using the phenomenographic method. The results show that students' experiences varied from considering the activity as (1) a coffee break or (2) peer-support, to seeing it as (3) identity construction or (4) a way of participating in a professional community. In further development of the model more emphasis should be placed on the integration of theory and practice.
\end{abstract}

Keywords: beginning teachers' induction, continuum of teacher development, phenomenography, peer group mentoring

The transition from teacher education to working life is recognized as a critical phase in the continuum of teachers' professional development (Kelchtermans \& Ballet, 2002; McKenzie, Santiago, Sliwka \& Hiroyuki, 2005; Stokking, Leenders, De Jong, \& Tartwijk, 2003; Tynjälä \& Heikkinen, 2011; Zuljan \& Požarnik, 2014). For decades research has highlighted the challenges new teachers face when entering the profession, and this professionally and emotionally demanding transition is often described in terms of 'reality shock' or 'practice shock' (Kane \& Francis, 2013; Stokking et al. 2003, Tynjälä \& Heikkinen 2011; Veenman, 1984). Tynjälä and Heikkinen (2011) have identified six common issues that new teachers encounter when transitioning from initial education to work: (1) threat of unemployment, (2) inadequate knowledge and skills, (3) decreased self-efficacy and increased stress, (4) early attrition, (5) uncertainty regarding the role and position of newcomers in the work community and (6) the importance of workplace learning. Another key cause of reality shock is seen to lie in the disconnect between university-based teacher education and everyday school life, reflecting the perennial tension between theory and practice in the teaching profession (Allen, 2009; Ball \& Forzani, 2009; Korthagen, 2010; Lewis, 2013; McMahon, Forde, \& Dickson, 2015; Zeichner, 2010). The Organization for Economic Cooperation and Development [OECD] (2011, p. 5) has identified the "limited connections between teacher education, teachers' professional development, and school needs" as one of the key points of stress in the continuum of teacher development and called for improved partnerships between teacher education institutions and schools in order to provide student teachers with a more integrated experience.

Recent decades have seen a surge in national and local induction programs aimed at supporting newly qualified teachers in their early career (Alhija \& Fresko, 2010; Heikkinen et al., 2008; Ingersoll \& Strong, 2011; Zuljan \& Požarnik, 2014). In many such programs beginning teachers go through an induction or training period before final graduation, which usually includes at least mentoring but often also observation, 
training seminars and formative assessment in addition to normal school work (Zuljan \& Požarnik, 2014). In Finland there is no such formal induction system, and on graduating from the five-year Master's teacher education program teachers are fully qualified in the profession. The core strength of the Finnish system is its high-quality and research-based initial teacher education program, with its objective of educating autonomous and critically reflective teachers (Hansén, Forsman, Aspfors, \& Bendtsen, 2012; Sahlberg, 2011; Välijärvi \& Heikkinen, 2012). Yet, beyond graduation, professional development varies and schools have no formal statutory system for inducting new teachers (Jokinen, Heikkinen, \& Morberg, 2012).

During the last decade, however, a new model of professional development, peer group mentoring (PGM), has been developed to support the professional learning of teachers in Finland in their early career. PGM differs from the traditional model of mentoring in its theoretical basis, which has direct consequences for how it is practically organized: whereas traditional mentoring is based on the idea of transferring knowledge from more experienced worker (mentor) to beginner (mentee), PGM is implemented in groups of novice teachers and their more experienced counterparts and is based on ideas of socio-constructivism, dialogue and knowledge sharing (Heikkinen et al., 2012; Kemmis et al., 2014).

PGM has previously been applied specifically as a method for promoting the professional development of working teachers, but is now recognized to have potential for various other purposes and target groups. The aim of the present study is to examine, from a teacher student viewpoint, a new model of teacher professional learning that uses the PGM method to combine pre-service and in-service teacher education. In this research we understand the concept of induction in a broad sense, covering the whole transition phase from final years of teacher education to first years in profession (see Swachten, 2015; Zuljan \& Požarnik, 2014). Thus, the model can be viewed as an induction method, but also more broadly as a professional development model for teachers in different phases of career, and actually the line between these two is consciously being blurred. The context of the study was Paedeia Café Finland, developed as part of the European PAEDEIA project (2012-2015) (Heikkinen et al., 2015; Korhonen et al., 2015). The aim of the project was to build bridges between teacher education and working life and to develop practices for supporting student teachers in the transition phase. Before describing the study in more detail, we will shortly discuss the continuum of teacher development, induction as a particular phase of the continuum, and peer group mentoring as a method for professional learning both during induction and in further career phases.

\subsection{The continuum of teacher professional development}

The professional development of teachers is increasingly conceptualized as a continuum of initial teacher preparation, induction and continuing professional development (Avalos, 2011; Day, 1999; Feiman-Nemser, 2001, McMahon et al., 2015; OECD, 2011). The idea behind the continuum approach is to move away from over-emphasis on initial preparation by distributing teacher learning and professional development across career stages, and to thus support and promote the lifelong learning of teachers. It recognizes that initial preparation cannot provide teachers with all the skills and knowledge they need in the profession, but instead can only lay the foundation and motivation for career-long development, preparing novices to learn in and from their practice (Feiman-Nemser, 2001). However, this continuity is frequently hampered by a 
lack of connecting tissue within and between the different stages of teacher education (Feiman-Nemser, 2001; Jokinen et al., 2012). Thus, as McMahon et al. (2015, p.163) put it, the reconceptualization of teacher development "as a journey and not a destination" requires rethinking of the purpose and pedagogy of teacher education in both the initial and further phases.

One way of renewing teacher education policies to better meet the ideals of the continuum approach is to develop new pedagogies that would bring university-based teacher education and schools closer to each other, into a continuous dialogue. For example, Zeichner (2010) has proposed the creation of 'hybrid spaces' and McMahon et al. (2015) 'rich pedagogies' in teacher education that would bring together prospective teachers, experienced teachers and teacher educators alike to work together in learning communities. Similarly, Wood (2012) has discussed the importance of "liminal spaces" in teacher development, referring to processes of transition and boundary crossing. According to McMahon et al. (2015), rich pedagogies would encompass practicefocused approaches that are collaborative and enquiry based, draw on the educational

heritage of social constructivism and build on the critical and reflective foundations laid down in the initial phase. In many ways these proposals reflect the wider paradigm of professional learning, emphasizing job-embedded and collaborative models that are based on the view that by developing processes of reflection and enquiry teachers develop their practice and continue to feel motivated about what they do (FeimanNemser, 2001; McMahon et al., 2015; Wei, Darling-Hammond, Andree, Richardson, \& Orphanos, 2009). What is also typical of these pedagogies is that they tend to blur the boundaries between formal and informal learning by recognizing and making use of the learning that takes place not only in the formal education institution, but in every sphere of life (Heikkinen et al., 2012; Wei et al., 2009).

Learning communities take a variety of forms, such as teacher study-groups (Carroll, 2005; Hung \& Yeh, 2013), communities of practice (Wenger, 1998), collaborative inquiry (Butler \& Schnellert, 2012), inquiry communities (Cochran-Smith \& Lytle, 1999) and collaborative action research groups (Burbank \& Kauchak, 2003). Also PGM can be regarded as one form of professional learning communities. Regardless of the name, the aim of such communities is to promote professional dialogue and inquiry together with colleagues from either same school or beyond it, with the ultimate aim of changing practices and social relationships in classrooms and schools, so that learning outcomes are maximized for all learners (Le Cornu, 2005). Previously, collaborative models of professional development have been typically focused on later stages of professional development, but are now being embedded also in initial teacher education in order to nurture in beginning teachers the rationale and skills associated with professional learning that will extend throughout their career (McMahon et al., 2015). As Le Cornu and Ewing (2008) argue, because learning to participate in professional learning communities is one of the most central factors in the ability of teachers to sustain their professional growth, it is crucial that beginning teachers learn how to participate in such communities already in pre-service teacher education.

\subsection{Induction as a phase of the continuum}

The induction phase of the professional development continuum constitutes an intermediating link between pre-service teacher education and continuing professional development (Geeraerts et al., 2015; Jokinen et al., 2012, Swachten, 2015). It is also 
recognized to have a great impact on professional development, professional efficiency, satisfaction, motivation and career duration of newly qualified teachers (FeimanNemser, 2001; McKenzie et al., 2005; Zuljan \& Požarnik, 2014). The concept of induction can be defined in three ways: 1 . induction as a process of learning to teach and professional development 2. induction as socialization and 3. induction as support provided for new teachers (Jokinen et al., 2012). Induction is typically considered to take place during the first years in the profession. However, in a broader sense, the culture of induction as socialization starts already in initial teacher education (Zuljan \& Požarnik, 2014). Thus, for example Hudson, Hudson and Adie (2015) argue that universities should commence induction programs earlier, already during the final year of study.

The three meanings of induction are closely related to each other, as the elements involved in "becoming and learning to be a teacher" and "teacher socialization" directly affect what kind of "induction as support" is needed. Moreover, the first two meanings can be positioned under the same title of "becoming a teacher", which includes professional, personal and social dimensions (Geeraerts et al., 2015; Eisenschmidt, 2006). This means that to become a teacher one has to absorb the skills and knowledge necessary in the profession, to construct a professional identity, and to relate to the professional community of teachers (Flores \& Day, 2006). So, in order to be a skilled teacher one must not only be familiar with teaching methods, curricula, learning theories and the content knowledge one is teaching, but also to recognize knowledge embedded in the operating environments and socially shared practices of the workplace (Heikkinen et al., 2012). Another important element in the process of becoming a teacher is becoming part of the discourse community of teachers, which can take place only by participating in such communities (Putnam \& Borko, 2000).

Mentoring is the most widely used induction method, and the terms induction and mentoring are even sometimes used interchangeably in the literature (Ingersoll \& Strong, 2011; Langdon, Alexander, Ryde, \& Baggetta, 2014). In its traditional form, mentoring refers to an expert-novice relationship whereby a more experienced person (mentor) gives support and advice to a less experienced colleague (mentee/actor) and facilitates his/her induction to the school culture (Heikkinen et al., 2008; Hobson, Ashby, Malderez, \& Tomlinson, 2009; Ingersoll \& Smith, 2004; Le Cornu, 2005). An important person in this process is a mentor who is responsible for providing support personally, socially and professionally. In their review of mentoring research, Hobson et al. (2009) listed a wide range of benefits of mentoring, including for example reduced feeling of isolation, increased confidence and self-esteem, professional growth, and improved self-reflection and problem solving capacities. However, the traditional form of mentoring has also gained some criticism. Besides its benefits, research also shows that some restricted forms of mentoring can result in the "promotion and reproduction of conventional norms and practices, rendering beginning teachers less likely to develop their knowledge and use of progressive and learner-centred approaches, and less likely to challenge the inherent conservatism in teaching or to advance social reform and social justice agendas" (Hobson et al., 2009, p. 211). As regards the organization of mentoring practices, one of the limitations is that the process is deeply individualized, resting on a dyadic relationship of learner and mentor, even though the trend is towards more communal development (Forde \& O'Brien, 2011). The term mentoring also connotes a hierarchical relationship between participants and a conservative view of learning, which assumes that knowledge is something that can be transferred from one person to another (Pennanen et al., 2016; Le Cornu, 2005). Thus, for beginning teachers it suggests an unidirectional socialization into the existing cultures of schooling 
(Pennanen et al., 2016) and can even be harmful for the development of their professional identities (Yuan, 2016).

\subsection{Reconceptualizing mentoring as collaborative professional development}

In response to critique and reflecting on the practices and current knowledge on professional learning, more collegial conceptions of mentoring have emerged during the last few decades, in which the mentoring relationship is recognized as more dynamic, collaborative and reciprocal (Heikkinen et al., 2012; Le Cornu, 2005; Shank, 2007). These approaches have been referred to as 'co-mentoring' (e.g. Kochan \& Trimble, 2000; Mullen, 2000) 'peer mentoring' (e.g. Le Cornu, 2005), or 'peer group mentoring' (Heikkinen et al., 2012) in order to emphasize an equal and collegial nature of mentoring relationship and recognizing that both the mentor and mentee can learn from the interaction (Heikkinen et al., 2012; Le Cornu, 2005). New models of mentoring have been implemented with pairs or groups of teachers from either the same or different career phases, including initial teacher education (Eriksson, 2013; Heikkinen et al. 2008; Le Cornu, 2005). At a general level, the changing conceptions of mentoring reflect a shift towards more constructivist and dialogical views of knowledge and learning (Heikkinen et al., 2008; Heikkinen et al., 2012).

In Finland, mentoring practices have been developed according to the peer group mentoring model (PGM) in which teachers from different career phases come together to learn from each other and learn together (Geerarerts et al., 2015; Heikkinen et al. 2012). PGM is a method that can be used in the induction phase but also at further stages of professional development. It is an activity involving teachers sharing and reflecting on their experiences, discussing problems and challenges they meet in their work, listening and encouraging one another. The aim of the meetings is to promote the mutual professional development and well-being of teachers through collaborative selfdevelopment (Kemmis et al., 2014). The PGM model draws the mentoring concept closer to that of professional learning community (PLC) and can indeed be viewed as an application of PLC, as a place where "participants become genuinely involved in one another's learning as well as their own, and are positioned as co-learners as they engage in professional dialogue with one other" (Le Cornu, 2005, p. 358).

The PGM groups are facilitated by experienced teachers who have completed a mentor training specially designed for peer group mentoring. This mentor education module has been developed and implemented by all the teacher education institutions all over Finland within a national program for teacher development (2010-17), funded by the Ministry of Education and Culture. The mentor education aims at providing the mentors with skills and capacities for promoting reflective professional dialogue in a group of teachers. The reflective dialogue is catalyzed by functional, participatory and creative methods which utilize multiple visual and literal materials, as well as different kinds of social play and interaction to inspire discussion and reflection. The aim of these methodologies is to promote narrative identity work and thus enable reflective professional development of teachers. One of the most important responsibilities of the mentor is to make sure that everybody's personal questions and issues will be given equally time and space in the meetings. The mentor-facilitator is also responsible for the schedule of the group. The groups meet six to eight times in an academic year, for about 1,5 to 2 hours at a time. In its first meeting the group devises a plan of action. The group may determine a common broad theme for the entire period lasting the whole 
academic year, or vary the topic in every meeting. The common themes may be, for example, the challenges of multiculturalism, collaboration with parents, curriculum design or innovative teaching methods, some to mention. The model reflects the Finnish educational culture, which is based on teachers' high autonomy and trust and, accordingly, a key starting point for PGM is the assumption that teachers are competent professionals with a high expertise and an ability to examine their work collaboratively in the groups. Usually the PGM-groups are open to all teachers who are willing to participate regardless the age or professional experience. The learning objectives and study plans are determined by the group itself, leading to highly self-directed learning, utilizing the personal competencies and interests of the group members. Accordingly, no elements of assessment are included and the mentoring groups work on a selfregulative and voluntary basis (Heikkinen et al., 2012).

One of the theoretical foundations of peer group mentoring is the critical constructivist tradition (Heikkinen et al., 2012; Wang \& Odell, 2007), which is based on two theoretical mindsets. The first of these is critical theory, aiming at learning to question existing knowledge, where "new teachers are encouraged to pose questions, challenge existing practices, and alter the way of acting as teacher" (Heikkinen et al., 2012 , p. 23). The second theoretical background idea is constructivism, according to which new knowledge is constructed by drawing upon individuals' prior knowledge, conceptions and beliefs. Furthermore, knowledge as such cannot be transferred between individuals because people always interpret new information on the basis of their prior experiences and ideas. In PGM, expertise is developed according to the model of integrative pedagogy (Heikkinen et al., 2012; Tynjälä, 2008). Since professional expertise is an integrated whole of theoretical, practical, self-regulative and sociocultural knowledge, the main idea of the model is to support the connection making and integration of these core elements of professionalism. In PGM this is done in a group of colleagues by sharing and reflecting on personal experiences (i.e. practical knowledge) from participants' workplaces and communities (sociocultural knowledge). Theoretical concepts and models (theoretical knowledge) are used in the reflective activities to deepen conceptual understanding of the matters discussed. This kind of reflection is also assumed to enhance participants' metacognitive and reflective skills and self-regulation (self-regulative knowledge).

\subsection{Paedeia Café - peer group mentoring for pre-service and in-service teachers}

The context of the present study was a new version of the Finnish PGM model that combines pre-service and in-service teacher education by inviting teacher students to the same mentoring groups with working teachers. The Paedeia Café professional development model was designed and organized as a part of the European PAEDEIA project in cooperation with the Department of Teacher Education at the University of Jyväskylä, Finland. The concept was first implemented in the academic year 20132014, and slightly revised versions of Paedeia Café were offered in 2014-15, 2015-16 and 2016-17.

The PAEDEIA (Pedagogical Action for a European Dimension in Educators' Induction Approaches) project (2012-2015) aimed at building bridges between teacher education and working life and developing practices for supporting new teachers' transition to working life on three levels: professional, social, and personal (Heikkinen et al., 2015; http://paedeia.net/). Five European countries (Denmark, Finland, Portugal, 
Sweden and Turkey) participated in the project and in three of these - Finland, Sweden and Turkey - local induction programs called Paedeia Cafés were piloted. The structure and theory for setting up the cafés was agreed by the project partners, but the organization of practical activities and working methods varied from country to country. In Sweden, Paedeia Cafés applied the learning dialogue method and were organized as common meetings for teacher students and novice teachers mentored by teacher educators (Martinsson \& Olsson, 2015). In Turkey, Paedeia Cafés were organized for teacher students, teacher educators and teachers using a many-to-many-mentoring model (Akyol \& Ulusoy, 2015). In Finland, which is the context for the present study, mixed PGM groups of pre-service and in-service teachers were applied.

The idea behind the Finnish Paedeia Café was to provide student teachers a chance to participate in a professional community of working teachers during their studies and in this way to promote intergenerational learning. The objectives set for the café were to 1) promote students' professional identity work 2) combine theoretical, practical, sociocultural and self-regulative knowledge following the concept and principles of integrative pedagogy and 3) empower students to take steps towards working life. From a wider viewpoint, the model was designed so that it would mirror a 'rich pedagogy' in teacher education that brings together teachers from different stages of their career to share viewpoints and expertise and to learn together.

In the Paedeia Café PGM model the groups consist of 2-3 students and 2-3 teachers and 1-2 trained mentor-facilitators. The groups meet approximately once a month, totaling 6-8 meetings per year. In the first meeting they decide on the group schedule and venue and, in some cases, the discussion topics for further meetings. Themes discussed usually focus on the specific needs and interests of the group members and vary between groups. However, certain common topics are typically discussed by nearly all groups. These general themes reflect the common concerns of new teachers related to well-being and coping at work, classroom management, collaboration with parents and colleagues, teachers' responsibilities and freedom, and professional development. Current pedagogical issues, such as inclusion, individualized teaching, curriculum design and digitalized learning, have also been common topics of discussion.

During the academic year the student participants are asked to keep learning diaries of their experiences in the group and to produce a reflective final report as a course requirement. For working teachers participation is entirely voluntary and the meetings take place after working hours, although teachers opting to participate are expected to commit fully to the group.

\subsection{Aim of the study}

The aim of the present study was to discover and describe the qualitatively different ways in which student teachers experienced Paedeia Café meetings. Such an understanding was considered important and useful for further development of this new model of teacher professional development. The research questions were:

1. How did the student teachers experience Paedeia Café meetings?

2. How did their experiences differ from each other? 
The phenomenographic method was used to examine student teachers' experiences of peer group mentoring. Phenomenography is a qualitative research approach that seeks to reveal the ways in which people understand or experience a given phenomenon (Kettunen, Vuorinen, \& Sampson, 2013; Marton \& Booth, 1997; Åkerlind, 2005). The aim of phenomenographic research is to reach what can be described as a collective understanding (i.e. a collection of all possible ways in which the target phenomenon can be understood among a certain group of people) rather than an individual state of mind (Marton \& Booth, 1997; Paakkari et al., 2011). In practice, this means that the outcomes of phenomenographic studies are based on the variation across all of the data transcripts, not on a categorization of each individual in the study (Ashwin, Abbas, \& McLean, 2014; Marton \& Booth, 1997; Åkerlind, 2005).

One of the central premises of phenomenography is its non-dualistic ontological perspective, according to which the world and people are considered inseparable (Bowden, 2005; Kettunen et al., 2013). This means that it is impossible to investigate the world or reality as such, separated from human interpretation. To highlight this point, the phenomenographic approach makes a distinction between a first-order perspective, studying reality, and a second-order perspective studying conceptions of reality. In phenomenography, the researcher always investigates the target phenomenon from the second-order perspective - not describing reality as such, but human conceptions of reality (Dahlin, 2007; Marton, 1986). This ontological premise holds true in most research approaches, although it may not always be as clearly articulated. Another basic idea in phenomenography, related to the inseparably of the human and the world, is that conceptions of reality or ways of understanding or experiencing are seen as relations between the person and a specific phenomenon in the world. They are not of an individual or psychological nature, located in the minds of particular human beings, but rather they are cultural, lying in the relations between people and the world (Dahlin, 2007; Kettunen et al., 2013).

The result of phenomenographic research is a set of categories of description, referred to as an "outcome space", which reflects the different conceptions expressed by participants in the study (Paakkari et al., 2015; Täks et al, 2014). The assumption is that different categories of description are logically related to one another and can be structured as an inclusive or nested hierarchy (Marton \& Booth, 1997; Åkerlind, 2012). The hierarchical nature of the outcome space means that the conceptions lower in the hierarchy represent less complex, advanced, powerful or sophisticated ways of experiencing something, whereas the conceptions higher in a hierarchy represent more complex, advanced, powerful, or sophisticated ways of experiencing the same phenomenon (Paakkari et al., 2015). Categories higher in the hierarchy may include aspects from categories lower in the hierarchy, but not vice versa (Täks et al., 2014).

In addition to identifying different categories of description, it is also important to identify the aspects that differentiate the categories from each other and reveal the quality differences between them. These aspects, called dimensions of variation, express and describe the difference between less and more complex conceptions (Paakkari et al., 2015). What is interesting from the viewpoint of educational practices is that some dimensions of variation can reveal what needs to be changed to gain a more complex or advanced way of understanding or experiencing the target phenomenon (Marton \& Booth, 1997).

As is the case in all qualitative research, the result of a phenomenographic study is always constituted in relation between the researcher and the data. Hence, the outcome 
space of a phenomenographic study is not the only possible outcome that could be constituted from the data. It only represents and argues for one interpretation about the phenomenon that is meaningful and reveals something new about the target phenomenon. What is important for the reliability of the study is that categories of description can be argued for convincingly on the basis of data (Ashwin et al., 2014; Åkerlind, 2012). In phenomenography, the quality of results, i.e. categories of description, can also be assessed in light of Marton and Booth's (1997, pp.125-126) following three criteria:

- Each category should describe something clear and distinct about the experienced phenomenon;

- Each category should stand in a clear and logical relationship to other categories, and

- There should be a limited, parsimonious number of categories to capture the variation in the data.

The data of this study consisted of reflective reports written by the student teachers who participated in the Paedeia Café Finland in the academic years 2013-2014 and 20142015. The participation was on voluntary basis, and the participants were recruited through an e-mail list targeted to teacher students. The department of Teacher Education permitted organizing this activity, and the students were asked for permission to use their writings as research material. The sample was 19 master's students of teacher education who were in the final phase of their studies. All of the participants had some experience of teaching, at least of teaching practicums included in their pedagogical studies. The reflective reports were gathered at the end of the semester after all the Paedeia Café meetings had been held. In the essay, students were asked to reflect on their experiences of Paedeia Café meetings and their professional growth as a teacher. The length of the reports varied from 6 to 14 pages. The essay assignment was as follows:

After the final meeting, write a 5-10 page report about your experiences of Paedeia Café. You can write either freeform or base your essay on the following questions:

(1) Why did you choose to apply for teacher education?

(2) What do you think about the teaching profession now?

(3) What is your view of teacher education?

(4) Why did you apply to Paedeia Café?

(5) What did you expect from it? 
(6) What did you learn? How did you experience the meetings?

(7) How has this experience affected your view of teaching and teacher education?

(8) How did your group work? What enhanced/constrained meaningful work in your group?

(9) What thoughts do you have now, as you graduate?

The analysis began by identifying and describing overall meanings that student teachers had given to Paedeia Café meetings. Statements found to be relevant to the question being investigated were selected, marked and coded. At this point there were dozens of codes/names for meanings expressed in the data that were not yet put into categories. In this process the phenomenon in question was narrowed down and interpreted in terms of these selected quotes, whose length varied from one sentence to a paragraph or a page. During the repetitive readings the data was treated as a whole and the boundaries between individuals were abandoned. However, the quotations were not cut off from their original context, as the context was considered important when interpreting the meaning of each quotation more closely.

In the second phase of the analysis the codes were grouped and regrouped into categories based on their similarities and differences in order to form a draft set of descriptive categories. The codes that were somehow close to each other such as "emotional support", "peerness", "encouragement", "notion of not being alone" and "sharing similar experiences" were put into same category and given a common denominator, in this case "peer support". Then the focus was turned to the aspects that differentiate categories from each other. The aim was to identify the dimensions of variation that distinguish one way of experiencing Paedeia Café from another. For example, it was found that there was some variation in how students described peer support and their wider relationships with other participants, and accordingly, one dimension of variation was named as "relationships between participants". Finally four descriptive categories were defined and the most characteristic features of each category were described, with constant reference to the data. The categories were organized in a hierarchical and inclusive structure based on both logical argument and empirical evidence. In concrete terms, the process followed Åkerlind's (2012, p. 118) description of analysis process: quotes were sorted into piles, borderline cases were examined, and eventually the criterion attributes for each group were made explicit. In this way the groups of quotes were arranged and rearranged, narrowed into categories and finally defined. During the analysis process it was kept in mind that one essay or quotation or even one sentence might contain more than one way of experiencing Paedeia Café.

The whole research process was designed to ensure no harm to the participants. The privacy and anonymity of the participants was guaranteed and no identifying information about the individuals was revealed during the research process. In the analysis, the researchers aimed to avoid misinterpretations by remaining honest to the original transcripts and their context and by using them as evidence for interpretations so that anyone can assess their truthfulness. 
On the basis of the data analysis, the respondents' experiences of Paedeia Café were grouped into four categories: (1) Paedeia Café as a coffee break, (2) Paedeia Café as peer-support, (3) Paedeia Café as identity construction and (4) Paedeia Café as a way of participating in a professional community. These qualitatively distinct categories were analyzed with respect to the following five themes: meaning given to the meetings, topics of discussion, relationship between theory and practice, relationship between participants and the main learning experiences gained in the group.

The outcome space is introduced in Table 1 in which the categories of description are structured as an inclusive and nested hierarchy. The first category reflects the narrowest way of experiencing Paedeia Café meetings and the fourth category reflects the most advanced, complex or deepest way of experiencing the same phenomenon. The inclusiveness of the hierarchy means that elements from the first category "coffee break" can be included in the category "peer support" and elements from "peer support" can be included in "identity construction". Finally, the category "professional community" includes elements from all the other categories. 


\subsection{Paedeia Café as a coffee break}

In the first category, Paedeia Café was conceived as a coffee break in the middle of daily life. Meetings were described as catching up with other group members over a cup of coffee and the main meaning given to the meetings was relaxation, unwinding, refreshment, chatting and amusement. The social aspect was conceived as important.

The meetings felt more like having a cup of coffee with friends than studying --- I always felt refreshed afterwards.

In our meetings the coffee had significant meaning. Our meetings were held in the afternoon, most often at 14.30-16.30, straight after the work and school day. Often we were little bit weary. The coffee and cake had a twofold meaning in our meetings. They refreshed us both physically and mentally and promoted a relaxed and joyful atmosphere.

Sometimes we could spend an hour just talking about whatever came to mind, before moving to the actual topic...

The topics of discussion in this category could be something related to teachers' work or studies, but not necessarily - for example weather, hobbies, family business or topical themes in media could be discussed about in addition to school and work. It was typical for this category that the discussion didn't seem to be goal-directed or reflective and it stayed on a superficial level. There were no theoretical views included in discussions and theory was seen to be un-useful and separate from practice. In this category, Paedeia Café was commonly experienced as a pleasant change from other university studies, which were conceived to be too theoretical and far from the day to day life of teachers - a view that was reinforced by the dominant discourse in this category.

In the group I realized that teacher education is quite far from the reality of the teacher's job and that the most important "school" for a teacher is working life.

The relationship between participants was casual and no deep relationships, typical of the categories higher in the hierarchy, were formed. Sometimes the changing group composition prevented the group formation.

One thing that constrained the group was that people were often absent.

The changing group composition prevented group formation, especially at the beginning of the semester.

Elements from this first category often described the beginnings of meetings, which took the form of informal catching up and unwinding before moving to more goal-oriented discussion. The relaxed and informal atmosphere typical of this category was a prerequisite for moving to the other categories higher in the hierarchy. As such, the "Paedeia Café as a coffee break" category reflects the narrowest experience of the meetings. If this remained the sole or 
dominant extent of the meeting the overall experience could be disappointing to the participants, especially if expectations were high.

My high expectations for the course were not fulfilled---We often spent most of the time just chatting and drinking coffee.

\subsection{Paedeia Café as peer-support}

In the second category, Paedeia Café was conceived as peer support and the main meaning given to the meetings was the emotional support that the participants received from each other. In this category the student teachers emphasized how useful it was to have a chance to share their thoughts and feelings with others who had gone through similar experiences. The support and encouragement of more experienced teachers was considered especially valuable.

It was encouraging and comforting to hear how the others had gone through similar feelings when starting their career as a teacher. I realized that excitement, fear and anxiety are normal reactions.

Topics of discussion often concerned practical experiences and problems faced in the teacher's work and the feelings that these evoked. Work rush and well-being, and student teachers' questions, concerns and fears were also considered important themes of discussion in this category. Often the discussion would start from a practical real-life case that someone had faced, and the perspective was then widened so that everybody could reflect on their own experiences and ideas about the phenomenon. However, this carried a risk that sharing negative experiences could start to resemble bemoaning if the perspective was not constructive. The discussion in this category can be described as practical and reflective, but it did not reach the integrative level at which theoretical ideas and concepts are used to conceptualize practical experiences. Instead, the relationship between theory and practice was dualistic and practice was valued over theory.

We talked about well-being and coping as a teacher, teachers' responsibilities and collaborating with parents. Theoretical perspectives didn't get much attention in our discussions.

Often we ended up talking about challenging situations like problems in classroom management. Sometimes it seemed that there are no means to solve these problems.

The main learning in this category was the understanding that you are not alone with your feelings and concerns. Students learned that sharing experiences can offer great relief and improve their well-being at work. They also gained a lot of confidence, which made the transition phase seem easier.

I'm not afraid of working life anymore---In the group I got some tools to reflect on my own well-being and coping at work. I know I'm not alone with these thoughts. I've learned to be compassionate with myself and I know how important it is to ask for help when it's needed. 


\subsection{Paedeia Café as identity construction}

In the third category, Paedeia Café was conceived as professional and personal identity work. The discussions and exercises carried out in the group promoted the participants' selfknowledge and gave them tools to reflect on who they are as individuals and teachers. The focus was on individual growth, which was supported by the group.

During the course I've started thinking about my own growth as a teacher and what my professionalism consists of. During this spring I've been updating my teaching philosophy intensively.

The exercises were done for oneself, but sharing was obligatory.

Topics of discussion that were considered meaningful in this category concerned values, principles, philosophical questions, own life history and future visions. The relationship between theory and practice was reflective and philosophical.

We examined our own professional identities, life histories and dreams by using pictures and narrative methods as tools.

It has also been useful to think about what things I don't want to renew in my own teaching.

The relationship between participants was collegial but also personal. The participants appreciated each other's otherness and the interaction was described as dialogical. In this category the most significant learning experiences were related to self-knowledge. Students told that they had learned more about themselves and gained new tools for identity work. They became aware of their values and principles and learned to share them with others. Many students also told that in Paedeia Café they had learned to understand and accept the incompleteness of an educator.

The Paedeia meetings gave me lot of tools for self-development and identity work. I learned to share my thoughts, to talk sincerely about my experiences and to take tips and advice from others.

One of the most important insights I had from the group was that as a teacher one can never be "ready".

\subsection{Paedeia Café as a professional community}

In the fourth and highest category, Paedeia Café meetings were conceived as participating in a professional community of teachers. The main meaning given to the meetings in this category was the sharing of ideas and experiences about teaching and school development. The discussions were described as constructive learning and sharing of expertise. Compared 
to the previous categories, communal development and learning, in particular, received more attention according to the students. Critical viewpoints were also included in the discussion. In this category elements from all of the other categories were combined, composing a multifaceted whole.

The Paedeia café represented a very rewarding way of learning. The discussions, held in a pleasant atmosphere, gave me a lot of advice and tools for my future career. It was easy to be in the group since you knew that you would be heard and you could draw a lot from others' experiences. It was great to have the feeling that we are on the same line, learning and guiding each other, even though our group consisted of students and teachers of different ages.

Different views and ideas inspired people to see things from different viewpoints, to question their own habits and to try something new.

The topics of discussion considered important in this category were related to teacher professionalism and the school community. The perspective was broad, covering everything from practical tips and ideas to the principles and values that form the basis of all school work. Meaningful topics included, for example, teaching methods, challenging situations faced at work, collegial and multi-professional collaboration, and values and principles.

Topics of discussion included development discussions, team-meetings, personal goals, giving and receiving feedback and being critical.

Even though we often agreed on many things and shared similar views, the meetings were not only about harmonious humming. Conflicting views of others did not feel like an attack on my own ideas, but instead they helped me in a positive way to question my own views and to understand some new viewpoints.

The relationship between theory and practice was integrative and critically reflective. Theoretical ideas and conceptions were applied to practical experiences and practical experiences were reflected on in light of educational theories. The student teachers emphasized the usefulness of the interaction between pre-service and in-service teachers, as in the discussions they could apply their theoretical knowledge to the practical experiences of the working teacher. The ideal of shared expertise was realized as everybody brought their own special knowledge and experience to the group and shared it with others. The relationship between participants was described as dialogical and collegial.

In the meetings the learning theories that the students had learned got combined with the teachers' field experiences. Everyone brought their expertise to the discussion and everyone could learn.

In our Paedeia group, the working teachers had more practical knowledge about teachers' work, but we students had a clearer picture about the things that are taught in teacher education. We could compare the practices in different schools based on our experiences as substitute teachers.

I think there was true collegiality and dialogue between our mentor and other participants. We all participated in the discussions as equals. 
In this category Paedeia Café offered students a chance to participate in a professional community of teachers already during their studies. Paedeia Café worked as a bridge between study and working life in a twofold sense: it supported the students' transition phase and also promoted mutual interplay between school and university. The students told that Paedeia Café broadened their understanding about education and school as a community. They gained communication skills and tools to develop their professionalism, teaching practices and future working community.

I felt I learned a lot from the others' experiences. The group discussions broadened my understanding about being part of a working community.

Peer group mentoring provided a unique opportunity for in-depth multiprofessional collaboration.

The learning was pleasant, interesting and continuous. Problems were shared and you got new solutions and viewpoints. Problems suddenly seemed much smaller. Different views provoked all the participants to see things from a different angle, to question their own way of doing things and to try something new. After each meeting I felt enlightened and well equipped to face new challenges.

Overall, the student teachers' experiences of participating in Paedeia Café peer mentoring group were positive and highlighted the importance of prospective teachers having authentic connections to working life and colleagues already during initial education. However, experiences varied in terms of depth and effectiveness and the kind of learning that they promoted. The phenomenographic analysis produced four different categories of description reflecting the students' different ways of experiencing the group: Paedeia Café as (1) a coffee break, (2) peer-support, (3) identity construction and (4) a professional community. The five dimensions of variation that differentiated these categories from each other were: meaning given to the meetings, topics of discussion, relationship between theory and practice, relationship between participants, and the main learning experiences gained in the group. The categories were hierarchical by nature and the depth of experience grew when moving from one category to another. In the first category the experience of participating in a Paedeia Café group was light and superficial and no learning was described, whereas in the highest category it was described as collaborative and constructive learning and sharing of expertise. However, none of the categories should be neglected as they all served a purpose as part of the overall experience. For example, the first category had a negligible impact on the students' professional development, but the informal feeling of being on a coffee break was important when moving to the higher categories. This first category promoted an open, sharing atmosphere and a sense of confidentiality and equity that were prerequisites for peersupport, identity work and mutual learning. Thus, the categories of description should be seen as a cumulative continuum in which each category brings something more to the overall experience. As Marton and Booth (1997) put it, different categories of description represent more or less complete ways of experiencing the whole.

Together, the four categories of description reflect well the objectives set for Paedeia Café, namely to 1) promote students' professional identity work 2) combine theoretical, practical, sociocultural and self-regulative knowledge following the idea and principles of integrative pedagogy (Heikkinen et al., 2012), and 3) empower students to take steps towards 
working life. However, to achieve all of these objectives students needed to experience all four of the categories of description, which was not always the case. Even though the categorization of each individual or numeral statistical assessment of the transcripts were not the aim of this research, three general remarks can be made about the frequency of different categories in the data: 1 . all participants had experiences from more than one category, 2. the experiences were cumulative by nature, so that the first category was the most common and the fourth the rarest, 3. almost all participants described experiences of a coffee break, peersupport and identity work, but not all of them reached the highest category of participating in a professional community.

In most cases the main reason for not reaching the highest category was a disconnect between theory and practice. The students' orientation was often more about learning from the practical experiences of working teachers and not so much about sharing their own expertise or integrating theoretical viewpoints into the discussion. Thus, it might be that regardless of the critical-constructivist design, the meetings sometimes fell to being more about reinforcing the existing school culture than transforming it. This has also been recognized in other studies on mentoring (Feiman-Nemser, 2001; Hobson et al., 2009) and relates to a common limitation of learning communities, described by Timperley (2008) as follows:

As an intervention on its own, a collegial community will often end up merely entrenching existing practice and the assumptions on which it is based. The research literature contains many examples of situations where teachers were given the time and resources to meet together to solve a problem or learn about new curricula or pedagogical practices but where this aim was thwarted by norms of politeness and the absence of challenge (p.19).

Another critical aspect that influenced whether the experiences of the students reflected the highest category was the relationships between participants. In all the categories students described the relations as equals, which was said to make the interaction easy. However, as Heikkinen et al. (2012) have noted, equality has three dimensions: existential, epistemological and juridical. Existential equality means the universal equality of all people as human beings, epistemological equality refers to the skills and knowledge people possess, and juridical equality to the rights and responsibilities they have. In Paedeia Café, the kind of equality experienced by the students influenced the kind of discussion and learning taking place in the group. In the first three categories equality was mainly existential, whereas in the fourth category equality was also epistemological, meaning that students felt that they were equals in terms of knowledge. This did not, however, mean that they thought they had similar knowledge to working teachers. Instead, they acknowledged that they possessed different kinds of expertise and viewpoints that were equally valuable and useful in the teaching profession and should therefore be shared with others. This kind of orientation promoted active and critically reflective participation in the group, which was a requirement for achieving the highest category. Thus, one of the main findings of this research was that in order to reach true "peerness" or collegiality, the student teachers should be encouraged to take an active role in the group. A similar point was made by Fox and Wilson (2015) who studied the process of beginning teachers building social capital in professional networks. They concluded that beginning teachers should be made aware that their attitudes and behavior affect (positively or negatively) their access to resources of support (affective and cognitive) and hence their development. Also, if new teachers are intended to serve as agents of change, transforming school cultures, a lot of work must be done both in initial education 
to support such a transformative agency and also in schools to promote an atmosphere open to new ideas.

In further development of the model it is important to put more emphasis on creating settings that would foster collegial relationship between participants and promote integration of different forms of knowledge, especially theoretical understanding with practical knowhow. The best way to do this would be to foster the professionalism of the mentor-facilitators, because they can have a great impact on the kind of interaction and learning taking place in the group. As it is noted also by Aspfors and Fransson (2015), it is important that the mentorfacilitators go through a training period, during which they become familiar with the principles of PGM and integrative pedagogy. In future development of the mentor education more emphasis should be placed also on providing them with practical tools and methods on how to integrate theoretical viewpoints to the practice-oriented discussion. As an implication for teacher education pedagogy and practice it would be important to create more opportunities for pre-service and in-service teachers to come together to learn from each other and learn together. Studies on intergenerational learning have shown that not only young teachers learn from their more experienced colleagues, but also experienced teachers can learn from beginning teachers (e.g. Geeraerts, Vanhoof, \& Van den Bossche, 2016). This kind of collaboration would foster the feeling of collegiality and epistemic equality of prospective teachers.

\subsection{Limitations of the study}

This research was based on a rather small data set $(n=19)$, which is nevertheless typical of qualitative research. It has been noted that when examining the ways of experiencing, the saturation point can be reached with relatively small data (e.g. Täks, 2015, p. 48-49). Therefore, it is typical for phenomenographic research that it is based on rather small set of data, either interviews or writings. The phenomenon under study was a small-scale piloting of a new form of teacher development, and the data collection covered the whole target group. Saturation point was reached during the first year and no new categories were found from the data of the second year, but this only strengthened the analysis. Based on a rather small sample and focusing on distinct practices, the research design does not allow transferability and generalizability of the results. However, it provides some understanding about the processes of students and teachers learning together. Another limitation of the study is that it only encompasses the experiences of the student participants and not those of the working teachers. Thus, a task for further research would be to study the experiences of the working teachers who participated in Paedeia Café groups.

\section{CONCLUSIONS}

Overall, the students' experiences of Paedeia Café show that participating in a mixed peer mentoring group of pre-service and in-service teachers can relieve student teachers' anxiety in the transition phase, provide tools for professional development and promote mutual interplay between schools and universities. The results also indicate that in further development more emphasis should be placed on integrating more theoretical and critical viewpoints into discussions about practical experiences in order to promote deeper learning. This study suggests that by using PGM as a method for combining pre-service and in-service teacher education, substantial benefits can be attained, including increased interaction 
between schools and universities, advanced culture of induction, and smoother transition from studies to working life. 


\section{REFERENCES}

Abu Alhija, F., \& Fresko, B. (2010). Socialization of new teachers: Does induction matter? Teaching and Teacher Education, 26, 1592-1597.

Akyol, H., \& Ulusoy, M. (2015). Towards small group mentoring in Turkey. In H. Heikkinen, L. Swachten \& H. Akyol (Eds.), Bridge over troubled water: New perspectives on teacher induction (pp.164-183). Ankara: Pegem Akademi.

Allen, J. M. (2009). Valuing practice over theory: How beginning teachers re-orient their practice in the transition from the university to the workplace. Teaching and Teacher Education, 25, 647-654.

Ashwin P., Abbas, A., \& McLean, M. (2014). How do students' accounts of sociology change over the course of their undergraduate degrees? Higher Education, 67, 219-234.

Aspfors, J. \& Fransson, G. (2015). Research on mentor education for mentors of newly qualified teachers: A qualitative meta-synthesis. Teaching and Teacher Education, 48, 75-86.

Avalos, B. (2011).Teacher professional development in Teaching and Teacher Education over ten years. Teaching and Teacher Education, 27, 10-20.

Ball, D. L., \& Forzani, F. M. (2009). The work of teaching and the challenge for teacher education. Journal of Teacher Education, 60, 497-511.

Bowden, J. (2005). Reflections on the phenomenographic team research process. In J. Bowden \& E. Walsh (Eds.), Doing developmental phenomenography (pp.11-31). Melbourne: RMIT University Press.

Burbank, M. D., \& Kauchak, D. (2003). An alternative model for professional development: Investigations into effective collaboration. Teaching and Teacher Education, 19, 499514.

Butler, D. L., \& Schnellert, L. (2012). Collaborative inquiry in teachers' professional development. Teaching and Teacher Education, 28, 1206-1220.

Carroll, D. (2005). Learning through interactive talk: A school-based mentor teacher study group as a context for professional learning. Teaching and Teacher Education, 21, 457473.

Cochran-Smith, M., \& Lytle, S. L. (1999). Relationships of knowledge and practice: Teacher learning in communities. Review of Research in Education, 24, 249-305.

Dahlin, B. (2007). Enriching the theoretical horizons of phenomenography, variation theory and learning studies. Scandinavian Journal of Educational Research, 51, 327-346.

Day, C. (1999). Developing teachers: The challenges of lifelong learning. London: Routledge.

Eisenschmidt, E. (2006). Implementation of induction year for novice teachers in Estonia. Dissertations on Social Sciences 25. Tallinn: Tallinn University Press.

Eriksson, A. (2013). Positive and negative facets of formal group mentoring: Preservice teacher perspective. Mentoring \& Tutoring: Partnership in Learning, 21, 272-291.

Feiman-Nemser, S. (2001). Preparation to practice: Designing a continuum to strengthen and sustain teaching. Teachers College Record, 103, 1023-1055. 
Flores, M. A., \& Day, C. (2006). Contexts which shape and reshape new teachers' identities: A multi-perspective study. Teaching and Teacher Education 22, 2019-2032.

Forde, C., \& O’Brien, J. (2011). Taking continuing teacher education forward. In C. Forde, \& J. O’Brien (Eds.), Coaching and mentoring: Developing Teachers and Leaders (pp. 8290). Edinburgh: Dunedin Academic Press

Fox, A.R.C., \& Wilson, E. G. (2015). Networking and the development of professionals: Beginning teachers building social capital. Teaching and Teacher Education, 47, 93107.

Geeraerts, K., Tynjälä, P., Markkanen, I., Pennanen, M., Heikkinen, H. L. T., \& Gijbels, D. (2014). Peer-group mentoring as a tool for teacher development. European Journal of Teacher Education, 38, 358-377

Geeraerts, K., Vanhoof, J., \& Van den Bossche, P. (2016). Teachers' perceptions of intergenerational knowledge flows. Teaching and Teacher Education, 56, 150-161.

Hansén, S.-V., Forsman, L., Aspfors, J., \& Bendtsen, M. (2012). Visions for teacher education - Experiences from Finland. Acta Didactica Norge, 6, 1-17.

Heikkinen, H.L.T., Jokinen, H. \& Tynjälä, P. (2008). Reconceptualising mentoring as a dialogue. In G. Fransson \& C. Gustafsson (Eds.), Newly qualified teachers in northern Europe. Comparative perspectives on promoting professional development (pp. 107124). Gävle: University of Gävle.

Heikkinen, H.L.T., Jokinen, H. \& Tynjälä, P. (2012). Teacher education and development as lifelong and lifewide learning. In H.L.T. Heikkinen, H. Jokinen \& P. Tynjälä (Eds.), Peer-group mentoring for teacher development (pp. 3-30). London: Routledge.

Heikkinen, H. L. T., Swachten, L. \& Akyol, H. (Ed.). (2015). Bridge over troubled water: New perspectives on teacherinduction. Ankara: Pegem Akademi.

Hobson, A.J., Ashby, P., Malderez, A., \& Tomlinson, P.D. (2009). Mentoring beginning teachers: What we know and what we don't. Teaching and Teacher Education 25, 207216.

Hudson, S., Hudson, P., \& Adie, L. (2015). The school-community integrated learning pathway: Exploring a new way to prepare and induct final-year preservice teachers. Improving Schools, 18, 221-235.

Hung, F-T., \& Yeh, H-C. (2013). Forming a change environment to encourage professional development through a teacher study group. Teaching and Teacher Education, 36, 153165 .

Ingersoll, R. M., \& Smith, T. M. (2004). Do teacher induction and mentoring matter? NASSP Bulletin, 88, 23-40.

Ingersoll, R. M., \& Strong, M. (2011). The impact of induction and mentoring programs for beginning teachers. A critical review of the research. Review of Educational Research, 31, 201-233.

Jokinen, H. Heikkinen, H. L. T., \& Morberg, Å. (2012). The induction phase as a critical transition for newly qualified teachers. In P. Tynjälä, M-L. Stenström \& M. Saarnivaara (Eds.) Transitions and transformations in learning and education (pp.169-185).

Netherlands: Springer. 
Kane, R.G., \& Francis, A. (2013). Preparing teachers for professional learning: Is there a future for teacher education in new teacher induction? Teacher Development, 17, 362379.

Kelchtermans, G., \& Ballet, K. (2002). The micropolitics of teacher induction. A narrative biographical study on teacher socialization. Teaching and Teacher Education 18, 105120.

Kemmis, S., Heikkinen, H., Fransson, G. Aspfors, J., \& Edwards- Groves, C. (2014). Mentoring of new teachers as a contested practice: Supervision, support and collaborative self-development. Teaching and Teacher Education 43, 154-164.

Kettunen, J., Vuorinen, R., \& Sampson Jr., J.P. (2013). Career practitioners' conceptions of social media in career services. British Journal of Guidance \& Counselling, 41, 302317.

Kochan, F.K., \& Trimble B. S. (2000). From mentoring to co-mentoring: Establishing collaborative relationships. Theory Into Practice, 39, 20-28.

Korhonen, H., Heikkinen, H. L. T., Kiviniemi, U. (2015). Peer-group mentoring in Finland. In H. Heikkinen, L. Swachten \& H. Akyol (Eds.), Bridge over troubled water: New perspectives on teacher induction (pp.122-146). Ankara: Pegem Akademi.

Korthagen, F.A.J. (2010). Situated learning theory and the pedagogy of teacher education: Towards an integrative view of teacher behavior and teacher learning. Teaching and Teacher Education, 26, 98-106.

Langdon, F. J., Alexander, P. A., Ryde, A., \& Baggetta, P. (2014). A national survey of induction and mentoring: How it is perceived within communities of practice? Teaching and Teacher Education, 44, 92-105.

Le Cornu, R. (2005). Peer mentoring: Engaging pre-service teachers in mentoring one another. Mentoring \& Tutoring: Partnership in Learning, 13, 355-366.

Le Cornu, R., \& Ewing, R. (2008). Reconceptualising professional experiences in pre-service teacher education: Reconstructing the past to embrace the future. Teaching and Teacher Education, 24, 1799-1812.

Lewis, T. (2013). Validating teacher performativity through lifelong school-university collaboration. Educational Philosophy and Theory, 45, 1028-1039.

Martinsson, E. \& Olsson, I. (2015). Learning dialogue in Sweden. In H. Heikkinen, L. Swachten \& H. Akyol (Eds.), Bridge over troubled water: New perspectives on teacher induction (pp. 147-163). Ankara: Pegem Akademi.

Marton, F. (1986). Phenomenography: A research approach investigating different understandings of reality. Journal of Thought, 21, 28-49.

Marton, F., \& Booth, S. (1997). Learning and awareness. London: Routledge.

McKenzie, P., Santiago, P., Sliwka P., \& Hiroyuki, H. (2005). Teachers matter: Attracting, developing and retaining effective teachers. Paris: OECD.

McMahon, M., Forde, C., \& Dickson, B. (2015). Reshaping teacher education through the professional continuum. Educational Review, 67, 158-178.

Mullen, C.A. (2000). Constructing co-mentoring partnerships: Walkways we must travel. Theory Into Practice, 39, 4-11. 
Organisation for Economic Cooperation and Development (2011). Teachers matter: Attracting, developing and retaining effective teachers. Pointers for policy development. Paris: OECD.

Paakkari, L., Tynjälä, P., \& Kangas, L. (2011). Critical aspects of student teachers' conceptions of learning. Learning and Instruction 21, 705-714.

Paakkari, L., Tynjälä, P., Torppa, M., Villberg, J., \& Kannas, L. (2015). The development and alignment of pedagogical conceptions of health education. Teaching and Teacher Education 49, 11-21.

Pennanen, M., Bristol, L., Wilkinson, J., \& Heikkinen, H. L.T. (2016). What is 'good' mentoring? Understanding mentoring practices of teacher induction through case studies of Finland and Australia. Pedagogy, Culture \& Society,24, 27-53.

Putnam, R. T., \& Borko, H. (2000). What do new views of knowledge and thinking have to say about research on teacher learning? Educational Researcher, 29, 4-15.

Sahlberg, A. (2011). Finnish lessons: What can the world learn from educational change in Finland? New York: Teachers College Press.

Shank, M. J. (2007). Mentoring among high school teachers: A dynamic and reciprocal group process. Mentoring and Tutoring: Partnership in Learning, 13, 73-82.

Stokking, K., Leenders, F., De Jong, J., \& Van Tartwijk, J. (2003). From student to teacher: Reducing practice shock and early dropout in the teaching profession. European Journal of Teacher Education, 26, 329-350.

Swachten, L. (2015). Being and becoming in teaching - Towards an ethics for self-cultivation in times of crisis and control. In H. Heikkinen, L. Swachten \& H. Akyol (Eds.), Bridge over troubled water: New perspectives on teacher induction (pp.22-94). Ankara: Pegem Akademi.

Täks, M. (2015) Engineering students' experiences of entrepreneurship education. A qualitative approach. (Doctoral dissertation, University of Tartu, Tartu). Retrieved from: http://dspace.ut.ee/handle/10062/45901

Täks, M., Tynjälä, P., Toding, M., Kukemelk, H., \& Venesaar, U. (2014). Engineering students' experiences in studying entrepreneurship. Journal of Engineering Education, 103, 573-598.

Timperley, H. (2008). Teacher professional learning and development. Educational Practices Series-18. International Academy of Education \& International Bureau of Education Paris. UNESCO.

Tynjälä, P. (2008). Perspectives into learning at the workplace. Educational Research Review 3, 130-154.

Tynjälä, P., \& Heikkinen, H. (2011). Beginning teachers' transition from pre-service education to working life. Theoretical perspectives and best practices. Zeitschrift für Erziehungswissenschaft, 14, 11-33.

Välijärvi, J., \& Heikkinen, H. L. T. (2012). Peer-group mentoring and the culture of teacher education in Finland. In H. L.T. Heikkinen, H. Jokinen \& P. Tynjälä (Eds.), Peer-group mentoring for teacher development (pp. 3-30). London: Routledge.

Veenman, S. (1984). Perceived problems of beginning teachers. Review of Educational Research, 54, 143-178. 
Wang, J., \& Odell, S. (2007). An alternative conception of mentor-novice relationships: Learning to teach in reform-minded ways as a context. Teaching and Teacher Education, 23, 473-489.

Wei, R. C., Darling-Hammond, L., Andree, A., Richardson, N., \& Orphanos, S. (2009). Professional learning in the learning profession. A status report on teacher development in the US and abroad (Technical report). Dallas TX: National Staff Development Council.

Wenger, E. (1998). Communities of practice: Learning, meaning and identity. Cambridge: Cambridge University Press.

Wood, P. (2012). Blogs as liminal space: Student teachers at the threshold. Technology, Pedagogy and Education, 21, 85-99.

Yuan, E. R. (2016). The dark side of mentoring on pre-service language teachers' identity formation. Teaching and Teacher Education, 55, 188-197.

Zeichner, K. (2010). Rethinking the connections between campus courses and field experiences in college- and university-based teacher education. Journal of Teacher Education 61, 89-99.

Zuljan, M. V., \& Požarnik B. M. (2014). Induction and early-career support of teachers in Europe. European Journal of Education, 49,192-205.

Åkerlind, G. S. (2005). Academic growth and development-How do university academics experience it? Higher Education, 50, 1-32.

Åkerlind, G. S. (2012). Variation and commonality in phenomenographic research methods. Higher Education Research \& Development, 31, 115-127. 